\title{
Assessing Quality of Education in Indian Schools on Six Key Performance Areas
}

\author{
Susan L. Hillman ${ }^{1}$, Kavita Anand ${ }^{2}$, Swati Gupta ${ }^{2}$ \\ Saginaw Valley State University ${ }^{l}$, Adhyayan Quality Education Services Pvt. Ltd ${ }^{2}$
}

\begin{abstract}
This paper describes initial findings from the first year of a five-year study on the Adhyayan Quality Standard (AQS) self-review and validation process for assessing the quality of education in Indian schools. The AQS is benchmarked on "what good looks like" internationally and contextualized for India. School performance is judged on six Key Performance Areas (KPAs) by a multiple stakeholder self-review team whose assessment is peer validated. Analysis of preliminary data is provided for all six $K P A s$ from the first round of the AQS process in 34 schools in India. In depth analysis of the two KPAs on Teaching and Learning, and The Curriculum examines strengths and areas for improvement across schools from different geographic locations and differing management structures. Findings distinguish granular aspects of the schools' performances. Conclusions suggest that while a variety of topics are taught, greater attention is needed to: provide quality literacy and numeracy programs with appropriately challenging work for students, extend learning beyond the classroom, and develop the quality of relationships among students and between teachers and students.
\end{abstract}

\section{Introduction}

Recently, countries around the world have enacted national mandates in education with the intent of improving the access and quality of education for children. Kumar and Sarangapani [1] and Velaskar [2] indicate the emphases of these mandates have highlighted issues of school attendance, infrastructure and resources, and curriculum, and are based on the prevailing perspectives and beliefs about the purpose of education. The Right of Children to Free and Compulsory Education Act (RTE) in 2009 [3] has brought the question of the quality of education in India to the forefront for the first time in Indian education policy. The RTE mandates access to education as a right for every child within 6-14 years of age, and specifies requirements for schools such as the number of days/hours of instruction, the teacher-student ratio, and infrastructure (e.g., separate toilets for boys and girls) [3]. What remains undefined in the RTE is the quality of instruction in the classroom, especially regarding interactions between teachers and students around the content that is taught. A more complete picture of the quality of education in India may be provided through the AQS and its process of self-review using a detailed diagnostic tool. This AQS diagnostic tool enables schools to understand, with evidence, aspects of quality education as they appear in the daily life of the school based on six KPAs. A five-year research study was developed to examine the impact of efforts to engage school stakeholder teams composed of school leaders, teachers, non-teaching staff, students, and parents, in a process of continuous self-review using the internationally benchmarked AQS, contextualized for schools in India. This paper will describe the AQS process and present and discuss initial results of all six KPAs from the first round of school reviews to help understand the existing status of quality education in Indian schools. An in depth analysis of two KPAs with lower overall performance is included to provide insight on specific challenges in these areas.

\section{AQS and the process of school self- review with external validation}

There are several models for school self-review internationally. Ehren, Altrichter, McNamara, and O'Hara [4] and Faubert [5] indicate there is little research on effective use of data from school evaluation for improving the quality of education, and existing research focuses on education in countries from the Organisation for Economic Cooperation and Development (OECD). The AQS was developed around six KPAs based on a variety of inspection regimes including Ofsted [6] and research reports (e.g., Barber and Mourshed [7]; Mourshed, 
Chijioke, and Barber [8]), and then contextualized for schools in India.

The AQS has six KPAs with internationally benchmarked standards for what "good" looks like in schools: 1) Leadership and Management; 2) Teaching and Learning; 3) The Child; 4) The Curriculum; 5) Community and Partnerships; and 6) Infrastructure and Resources. An accompanying diagnostic tool includes three Key Questions (KQs) for each KPA. Each KQ is composed of three SubQuestions (SQs), and each SQ has three descriptive statements. In all, across the six KPAs, there are 162 descriptive statements. The school self-review process requires a multiple stakeholder team to rate each statement, SQ, KQ, and KPA on a four-point scale of "Outstanding", "Good", "Variable", and "Needs Attention".

The process of school self-review identified school strengths and areas for improvement. This enabled each school to develop evidence-based school improvement plans in a two-year cycle of self-review with external validation. Teams of school stakeholders were trained to conduct school selfreviews using evidence-based methods of observation while walking throughout the school facilities and grounds during school hours, observing classroom instruction, interviewing stakeholders (e.g., school leaders, teachers, non-teaching staff, students, and parents), and reviewing artifacts (e.g., notebooks, lesson plans, and school records). The school self-review teams conducted school selfreviews within two days, followed by external reviews for validation conducted by trained teams of assessors with extensive school experience using the same diagnostic tool and evidence collection methods. Dialogue between each school team and external team occurred after the reviews to discuss the evidence for ratings on the descriptive statements from the AQS diagnostic tool. Strengths to celebrate, and areas to improve were identified by each school team, supported with evidence from the reviews. Training on the process of action planning was also provided to each school self-review team composed of multiple stakeholders, with the intention of increasing ownership toward school improvement. A quality award valid for two years, from highest to lowest, of Platinum, Gold, Silver, or Bronze was determined from the evidence and awarded to the school by the external assessor team.

Preliminary analysis of the results from the initial AQS external school reviews indicated that $65 \%$ of the schools participating in this research study were rated with "Outstanding" (3\%) or "Good" $(62 \%)$ on the first KPA Leadership and Management, showing the strongest positive results among the six KPAs. Even though all but three schools received Quality Awards of Gold or Silver, the weakest performance occurred in KPA 2 Teaching and Learning with 20\% rated "Good" with no "Outstanding" ratings, and
$26 \%$ of schools rated "Outstanding" or "Good" on KPA 4 The Curriculum (see Fig 1). Performance ratings of "Outstanding" or "Good" on the other KPAs included KPA 3 The Child (50\%), KPA 5 Community and Partnerships (44\%), and KPA 6 Infrastructure and Resources (47\%). This paper will draw attention to the areas of challenge for schools within each KPA for providing quality education to children.

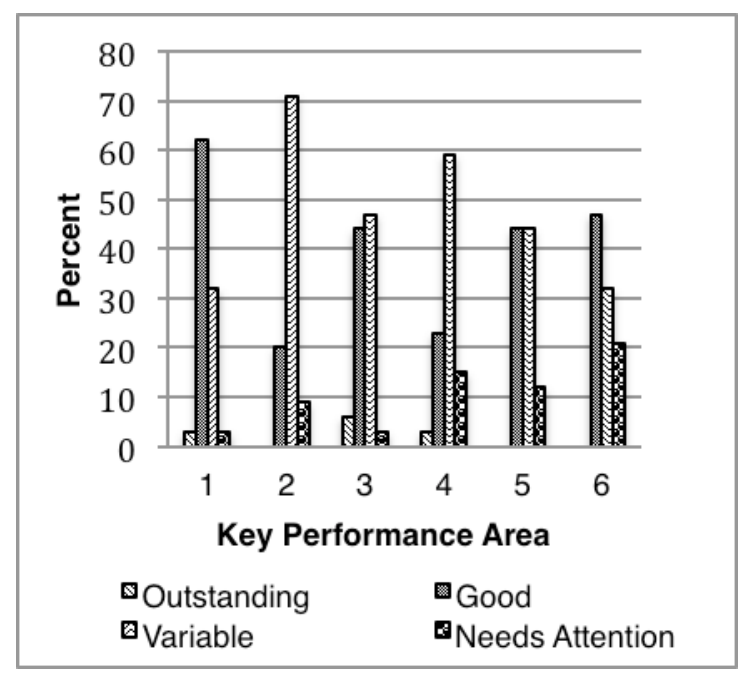

Figure 1. Overall KPA performance

\section{Methods}

There were 34 participating schools in India that undertook the AQS process, representing variability in type of school management, geographic location, cost, alignment to specific curriculum boards, network of schools or independent school, and AQS Award. The scope of this paper will report generally across all six KPAs and then focus only on the variables for type of school management, and geographic location for the two KPAs with the lowest performance. The type of school management was identified as government $(\mathrm{N}=4)$, mixed management by government and private entities $(\mathrm{N}=5)$, and private $(\mathrm{N}=25)$. Geographic location was identified as rural $(\mathrm{N}=3)$, urban $(\mathrm{N}=25)$, and peripheral to urban areas $(\mathrm{N}=6)$. All data collected were part of the AQS process. All data was aggregated and analyzed anonymously so that no single school could be identified from the data.

The results from AQS Reports generated by the external teams of initial school reviews in 2014 were the primary source of data for the analysis addressed in this paper. By the end of the study, each school should have completed three AQS award cycles. The results were analyzed using the ratings on each of the KQs and SQs from the diagnostic tool to determine the current status of quality on the six KPAs. Table 1 lists the KQs that define each KPA. 
Table 1. KPA Key Questions

\begin{tabular}{|l|}
\hline KPA 1 Leadership and Management \\
\hline KQ 1. How well is the school led? \\
\hline KQ 2. Is the school effectively and efficiently \\
managed? \\
\hline KQ 3. Is the school's culture and ethos robust \\
and pervasive? \\
\hline KPA 2 Teaching and Learning \\
\hline KQ 1. What is the classroom environment like? \\
\hline KQ 2. How good are the relationships in the \\
classroom and school? \\
\hline KQ 3. How good is the quality of the children's \\
learning? \\
\hline KPA 3 The Child \\
\hline KQ 1. What voice does the student have in the \\
School? \\
\hline KQ 2. Do children enjoy school and how well do \\
they achieve? \\
\hline KQ 3. Are students secure and healthy? \\
\hline KPA 4 The Curriculum \\
\hline KQ 1. How well is literacy and numeracy taught \\
and learned? \\
\hline KQ 2. How wide is the range of subjects taught? \\
\hline KQ 3. How rich is the learning of students \\
beyond the classroom? \\
\hline KPA 5 Community and Partnerships \\
\hline KQ 1. Do families partner with the school in \\
children's learning? \\
\hline KQ 2. How effective is the students' community \\
engagement? \\
\hline KQ 3. Do effective wider community and \\
volunteer links exist? \\
\hline KPA 6 Infrastructure and Resources \\
\hline KQ 1. How well is the school maintained? \\
\hline KQ 2. How effectively are resources used? \\
\hline KQ 3. How secure is health and safety? \\
\hline
\end{tabular}

Secondary sources of data included field notes from observations, stakeholder interviews, or artifacts from the AQS process and any follow up visits to schools.

A four-point scale (i.e., "Outstanding", "Good", "Variable", and "Needs Attention") was applied to each specific descriptive statement based on evidence collected from the school reviews. Ratings from the specific descriptive statements were used to determine ratings on SQs, KQs, and KPAs. A rating of "Outstanding" required evidence that showed consistency of high quality on specific indicators across the school (all levels and subjects) from all sources of evidence; a rating of "Good" required evidence to support a majority of high quality performance on indicators from more than one source of evidence. A rating of "Variable" indicated that there was some evidence of higher quality performance and some evidence of lower quality of performance on an indicator (i.e., the performance was variable across the school, across levels, or across subjects). The rating of "Needs Attention" indicated evidence that showed a majority of poor quality performance. Analysis included comparing frequency counts of ratings on the overall KPAs, the KQ within the KPAs, and the SQs within each KQ. The analysis of these ratings was used to better understand the status of quality education existing in schools.

\section{Results}

Ratings from the AQS Reports generated by the external assessor teams were analyzed and reported here. The results were analyzed from the ratings of KQs and SQs from the AQS diagnostic tool to determine the current status of quality of schools based on the KPAs. Results are organized by KPA. Areas of strength and areas that appear to be challenges for schools are identified for each KPA based on KQ ratings and SQ ratings within each KQ. Detailed analysis based on sorting schools by types of management and geographic location focused on KPA 2 Teaching and Learning and KPA 4 The Curriculum as the performance in these two areas appears to be the most challenging for schools. This level of analysis helped to further understand the particular challenges in these areas.

\subsection{KPA 1 Leadership and Management}

Analysis of the ratings for KPA 1 Leadership and Management, indicated that schools performed best on KQ 2 regarding the administration and management of the school where $76 \%$ of schools were rated "Outstanding" (38\%) or "Good" (38\%). Lowest performance on KPA 1 was on KQ 1 regarding the leadership and management of teaching and learning where $61 \%$ of schools were rated as "Variable" (See Fig 2).

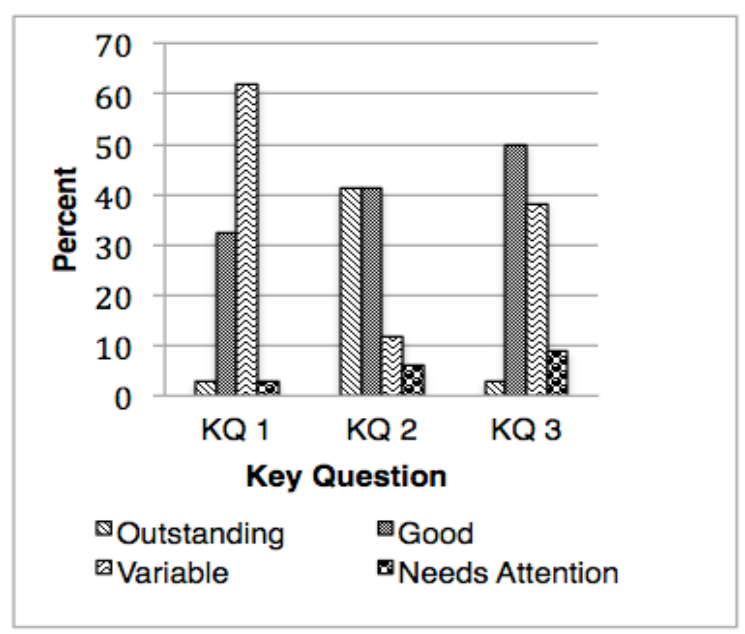

Figure 2. KQ performance on KPA 1

Further analysis of SQs within the KQs on KPA 1 reveal that areas of strength show $70 \%-79 \%$ of schools with ratings of "Outstanding" or "Good" 
within KQ 2 that include systems in place for organizing the learning day, employees understanding their roles and are accountable, and systems are effective for tracking student progress and reporting to parents. Areas that were challenging for schools were identified with more than $50 \%$ of schools rated as "Variable" or "Needs Attention" in KQ 1 related to school leaders visibly providing direction and promoting the school's values, and effectively organizing training programs for staff, and in KQ 3 related to staff and students having a voice in how the school is run.

\subsection{KPA 2 Teaching and Learning}

Analysis of ratings on KPA 2 Teaching and Learning shows none of the 34 schools achieved an "Outstanding" rating, $20 \%$ of the schools achieved a rating of "Good", 71\% of the schools achieved a rating of "Variable", and 9\% of the schools achieved a rating of "Needs Attention" (see Fig 1). A closer look at KPA 2 through analysis of the three KQs in Teaching and Learning revealed that more than $50 \%$ of the schools achieved a rating of "Good" or "Outstanding" on KQ 1 regarding the classroom environment, while $68 \%-82 \%$ of the schools achieved a rating of "Variable" or "Needs Attention" on KQ 2 for relationships in the classroom and school, and KQ 3 on the quality of children's learning (see Fig 3).

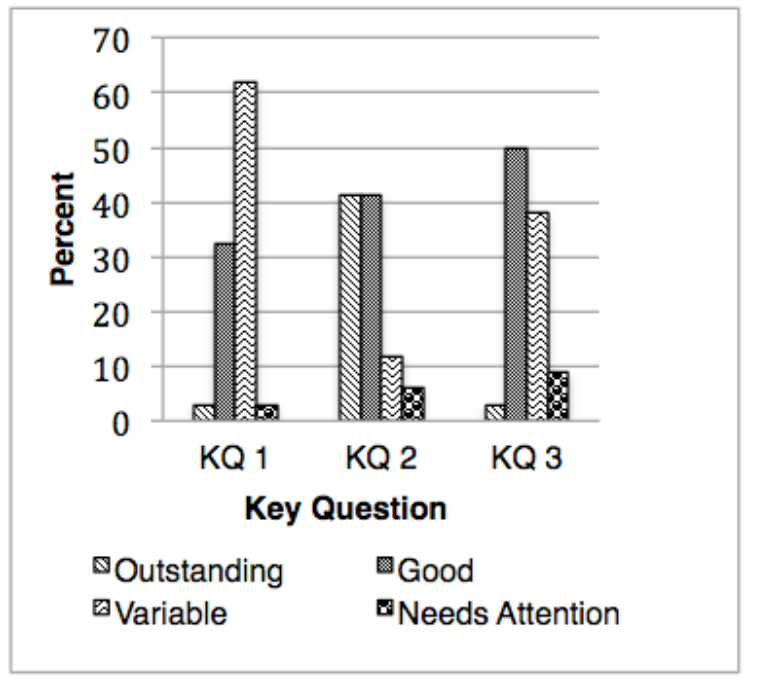

Figure 3. KQ performance on KPA 2

Table 2 lists the nine SQs for KPA 2 Teaching and Learning where the first three SQs elicit evidence for KQ 1, the next three for KQ 2, and the last set of three SQs for KQ3. Further analysis of SQs from KQ 2 on relationships in the classroom and school showed that the most challenging area was SQ 6 for considering the learning and social needs of students where $88 \%$ of schools received a rating of "Variable" (21\%) or "Needs Attention" (68\%).
Analysis of the SQs from KQ 3 regarding the quality of children's learning indicated that the most challenging area was SQ 7 with providing appropriately challenging work to students where $94 \%$ of schools achieved a rating of "Variable" (50\%) or "Needs Attention" (44\%).

Table 2. KPA 2 Teaching and learning

SQ 1. Is the environment bright and welcoming and does it promote good learning?

$S Q 2$. Dare the furniture and learning resources attractive and user friendly?

SQ 3. Is there a wide range of quality display of student work?

SQ 4. Do good relationships exist between

students who help each other to learn?

SQ 5. Are classes well managed and do teachers know students' learning and social needs?

SQ 6. Are the learning and social needs of the students supported by adults in the school and the classroom?

SQ 7. Are students being presented with work that challenges them?

SQ 8. Are all students regardless of ethnicity, religion or gender equally engaged and interested?

SQ 9. Is students' written work well presented and regularly marked by their teachers?

4.2.1. Results of KPA 2 for School Management. Schools from all types of school management achieved lower ratings within KPA 2 Teaching and Learning regarding KQ 1 , SQ 3 on the range of quality display of students' work in the classroom and school, and KQ 3, SQ 7 for providing appropriately challenging work to students. Government schools had ratings only at the "Variable" (50\%) or "Needs Attention" (50\%) levels regarding the regular marking of students' work from KQ 3, SQ 9. The schools with mixed management had ratings only at the "Variable" level (100\%) regarding classroom management for students' learning and social needs (KQ 2, SQ 5), and only at the "Needs Attention" level (100\%) regarding support for specific learning and social needs by adults in the school and classroom (KQ 2, SQ 6). The private schools received lower ratings on the same elements as schools with mixed management, with $68 \%$ that received a rating of "Needs Attention" regarding support for specific learning and social needs by adults in the school and classroom (KQ 2, SQ 6).

4.2.1 Results of KPA 2 for geographic location of schools. The data analysis on KPA 2 Teaching and Learning for schools sorted by geographic location revealed that $83 \%$ of rural schools achieved a "Variable" rating, and the remainder of rural schools achieved a "Good" rating. All schools on the periphery of urban areas were rated as "Variable" on 
KPA 2. Urban schools were divided where $24 \%$ of schools achieved "Good" ratings, 64\% of schools achieved "Variable" ratings, and $12 \%$ of schools achieved "Needs Attention" ratings for KPA 2.

At the analysis level of KQs for KPA 2 Teaching and Learning, KQ 1 on the classroom environment showed $84 \%$ of rural schools achieved ratings of "Outstanding" (17\%) or "Good" (67\%). KQ 2 on relationships showed $67 \%$ of rural schools achieved a "Variable" rating, and KQ 3 on the quality of children's learning showed $100 \%$ of rural schools achieved ratings of "Variable" (67\%) or "Needs Attention" (33\%). All schools on the periphery of urban areas showed a similar pattern where more than $50 \%$ achieved "Good" ratings on KQ 1 , and $67 \%$ to $100 \%$ of schools achieved "Variable" or "Needs Attention" on KQ 2 and KQ3. More than $50 \%$ of urban schools had ratings at the "Variable" or "Needs Attention" levels for all three KQs. Detailed analysis at the SQ level revealed consistency in three areas of concern including SQ 3 regarding the quality display of student work, SQ 6 regarding the support by adults in the school of children's learning and social needs, and SQ 7 regarding appropriately challenging work for students.

\subsection{KPA 3 The Child}

Analysis of the ratings for KPA 3 The Child show the best performance on KQ3 regarding the relationships in the school that enhance the safety and security of the students with $17 \%$ of schools rated "Outstanding" and $60 \%$ of schools rated as "Good" (see Fig 4).

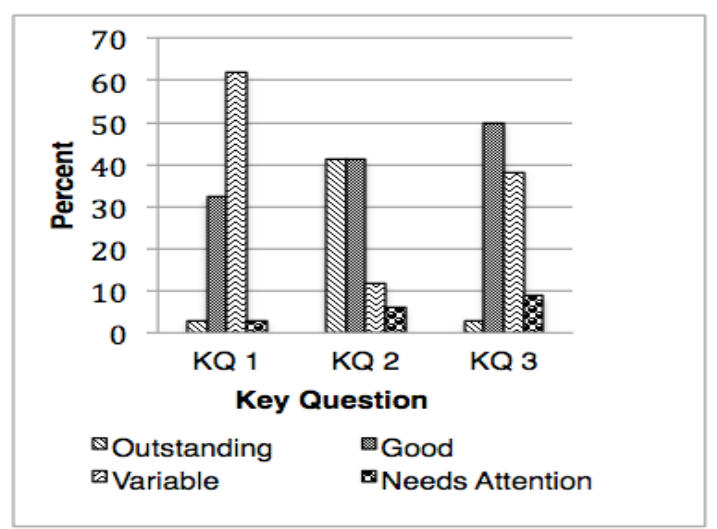

Figure 4. KQ performance on KPA 3

The lowest performance was on KQ1 regarding the voice of the child in the school where $2 \%$ of schools were rated "Outstanding", $24 \%$ of schools were rated "Good", 50\% of schools were rated "Variable", and $19 \%$ of schools were rated as "Needs Attention." KQ2 regarding children's enjoyment and achievement shows $62 \%$ of schools were rated as "Variable", and 38\% of schools rated "Good."
Further analysis at the SQ level within KQs highlight strengths. The SQs supporting KQ3 all have more than $50 \%$ of schools rated as "Outstanding" or "Good". Especially strong performance is found on SQ 7 regarding students feeling safe and secure at school with $59 \%$ of schools rated "Outstanding" and $32 \%$ of schools rated "Good." It is interesting to note that $71 \%$ of schools were rated as "Good" and $9 \%$ of schools rated as "Outstanding" on SQ4 within KQ2, with the remaining $20 \%$ of schools rated as "Variable." Performance on the other two SQs within KQ2 was not as high $(67 \%$ to $88 \%$ of the schools rated "Variable" or "Needs Attention" for SQ5 and SQ6 respectively, contributing to the overall variability in performance. The most challenging area for schools within KPA 3 was SQ1 regarding the involvement of children in putting together school rules with $68 \%$ of schools rated as "Needs Attention."

\subsection{KPA 4 The Curriculum}

Analysis of the ratings from KPA 4 The Curriculum, showed that one school (3\%) achieved a rating of "Outstanding", $23 \%$ of the schools achieved a "Good" rating, 59\% achieved a rating of "Variable", and 15\% achieved a rating of "Needs Attention" (see Fig 1). Further analysis of the KQs for The Curriculum revealed that 1-4 schools achieved an "Outstanding" rating on at least one of the KQs. The results showed that KQ 2 on the range of subjects taught was an area of relative strength where more than $50 \%$ of schools achieved a rating of "Outstanding" (12\%) or "Good" (41\%). Analysis of KQ 1 regarding how well literacy and numeracy was taught showed $79 \%$ of schools with ratings of "Variable" (67\%) or "Needs Attention" (12\%), and analysis of KQ 3 regarding the quality of learning beyond the classroom showed $71 \%$ of schools with ratings of "Variable" (26\%) or "Needs Attention" (45\%). These two areas of KPA 4 The Curriculum indicated areas of concern (see Fig 5).

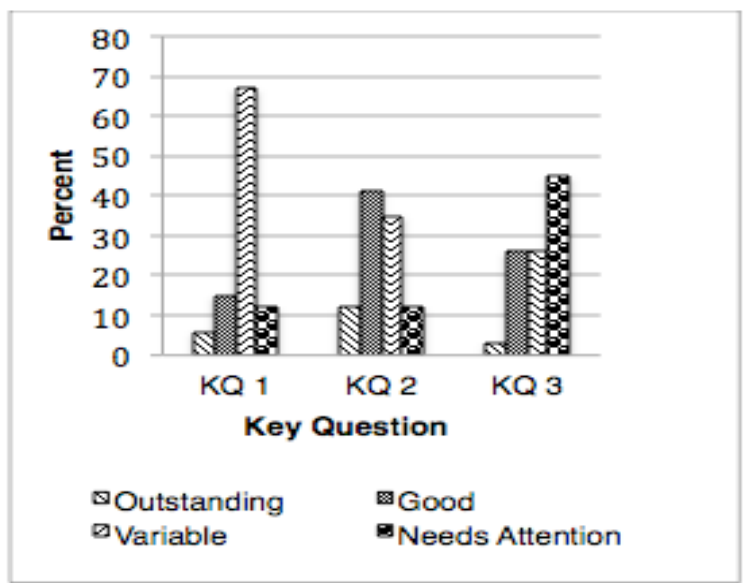

Figure 5. KQ performance on KPA 4 
Table 3 lists the SQs for KPA 4 The Curriculum. Analysis of the SQs from KQ 1 indicated 74\% - 79\% of the schools received ratings of "Variable" or "Needs Attention", in all three SQs. The analysis of the SQs from KQ 3 on the richness of learning beyond the classroom showed more than threefourths of the schools received ratings of "Variable" or "Needs Attention" for SQ 7 on visitors in schools $(82 \%)$, and for SQ 9 on field trips that support learning $(79 \%)$.

Table 3. KPA 4 The curriculum

SQ 1. Does the school provide well for literacy teaching?

$S Q$ 2. Does the school provide well for numeracy teaching?

SQ 3. Is there evidence of children having fun in their learning?

SQ 4. Does the curriculum offer a varied range of subjects?

SQ 5. Does the curriculum give opportunities to explore local, national and global issues?

SQ 6. Does the curriculum help promote spiritual, moral and social values?

SQ 7. Are learning opportunities enriched by visitors to the school?

SQ 8. Do students visit places of interest to support their studies?

SQ 9. Are after school activities provided on the site?

4.4.1 Results of KPA 4 for School Management. The analysis of KPA 4 The Curriculum revealed all of the government schools had ratings of "Variable" $(50 \%)$ or "Needs Attention" (50\%), schools with mixed management had a majority of schools $(67 \%)$ rated as "Good" and $33 \%$ of schools rated as "Variable". About one-fourth of the private schools (24\%) were rated as "Outstanding" (4\%) or "Good" $(20 \%)$, and $76 \%$ were rated as "Variable" $(64 \%)$ or "Needs Attention" (12\%). The analysis of KQs for The Curriculum showed that more than $50 \%$ of schools with mixed management had ratings of "Good" (60\% - 100\%) for KQ 2 (range of subjects taught) and KQ 3 (richness of learning beyond the classroom). Private schools and government schools had $75 \%-76 \%$ of schools with ratings of "Variable" or "Needs Attention" for KQ 3. All types of school management had three-fourths or more of the schools rated as "Variable" or "Needs Attention" for KQ 1 (quality of literacy and numeracy taught and learned). The analysis at the SQ level supported the KQ analysis with the schools of mixed management showing strengths in SQs related to the second and third KQs, and the government and private schools showing areas of concern in all SQs with one exception for private schools in SQ 4 (range of subjects offered in the curriculum) that showed $92 \%$ of private schools rated as "Outstanding" $(56 \%)$ or "Good" (36\%).
4.4.2. Results of KPA 4 for Geographic Area. The data analysis on KPA 4 The Curriculum for geographic location revealed that more than $50 \%$ of all the schools, regardless of geographic location, received ratings of "Variable" or "Needs Attention". Analysis at the level of KQs, revealed some differences. KQ 2 (range of subjects taught) was an area to celebrate for a majority $(60 \%)$ of urban schools and schools on the periphery of urban areas (67\%) with ratings of "Outstanding" or "Good". All of the KQs for rural schools showed $73 \%-100 \%$ of schools with ratings of "Variable" or "Needs Attention". Further analysis on SQs revealed SQ 4 (range of subjects offered) as an area to celebrate for schools in all geographic areas with $80 \%-100 \%$ of schools with ratings of "Outstanding" or "Good". Areas of concern for urban schools included SQ 1 on literacy teaching, SQ 7 on supporting learning with visitors to schools, and SQ 8 on field trips for students that support learning, with $76 \%-84 \%$ of schools achieving ratings of "Variable" or "Needs Attention" on each of these items. All of the rural schools had ratings of only "Variable" or "Needs Attention" for SQ 2 (numeracy teaching), SQ 3 (fun in learning), and SQ 6 (spiritual, moral, and social values). All schools on the periphery of urban areas scored the lowest on SQ 3 regarding evidence of children having fun in their learning.

\subsection{KPA 5 Community and Partnerships}

Performance on KQs from KPA 5 Community and Partnerships shows very strong performance on KQ1 with significant challenges on KQ 2 (see Fig 6).

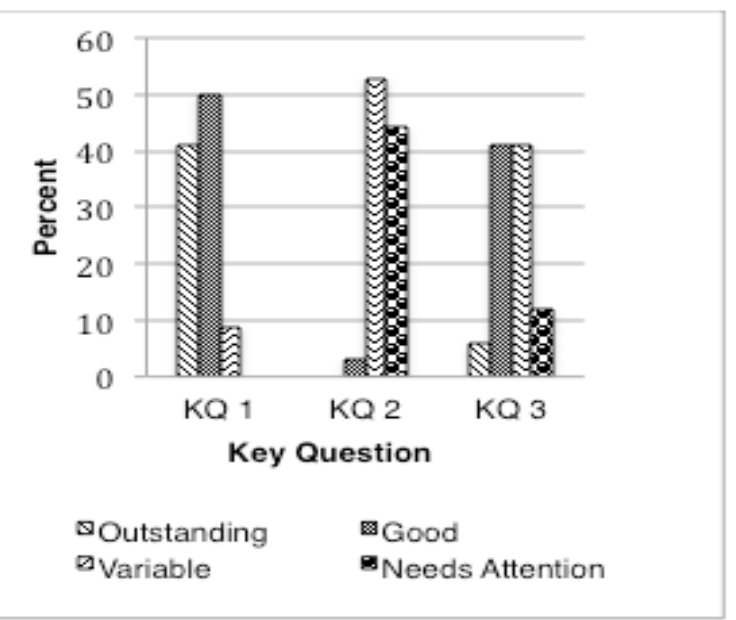

Figure 6. KQ performance on KPA 5

Analysis of ratings on the KQs from KPA 5 revealed that schools performed best on KQ1 regarding the involvement of families in the learning of the students with $40 \%$ of the schools rated "Outstanding" and 50\% of schools rated "Good." The lowest performance was on KQ2 regarding 
community engagement in which none of the schools achieved a rating of "Outstanding", 2\% of schools were rated "Good", 52\% of schools were rated "Variable", and $44 \%$ of schools were rated "Needs Attention." Performance on KQ3 regarding links with the wider community was mixed with nearly the same number of schools achieving "Outstanding" or "Good" compared to schools rated "Variable" or "Needs Attention" (see Fig 6).

Clear areas of strength appear in KQ1 from SQ2 for providing information to parents explaining the curriculum (44\% rated "Outstanding" and 35\% rated "Good"), and in KQ3 from SQ7 on opportunities for links with other schools (24\% rated "Outstanding" and $41 \%$ rated "Good"). The SQ analysis in KQ2 indicate $94 \%$ - 97\% of schools were rated "Variable" or "Needs Attention" on the curriculum promoting an understanding of the local community and involving students in the local community (respectively), and 68\% of schools rated "Variable" or "Needs Attention" on the community taking part in the life of the school.

\subsection{KPA 6 Infrastructure and Resources}

Analysis of the ratings in KPA 5 Infrastructure and Resources show relatively strong performance on KQ1 and weaker performance on areas from KQ2 and KQ3 (see Table 4). The performance on KQ1 regarding the maintenance of the schools showed $70 \%$ of schools rated "Outstanding" $(9 \%)$ or "Good" (61\%). The lowest performance was from KQ3 (74\% rated "Variable" or "Needs Attention") in the area of health and safety provisions such as evacuation procedures and transport facilities. There were no schools rated as "Outstanding" on KQ3. Performance on KQ2 regarding the effective use of resources showed $29 \%$ of schools were rated "Good", $53 \%$ of schools were rated "Variable", and the remaining schools were rated as "Needs Attention."

Table 4. KPA 6 Infrastructure and Resources

\begin{tabular}{|l|r|r|r|r|}
\hline & $\begin{array}{r}\text { Out- } \\
\text { standing }\end{array}$ & Good & Variable & $\begin{array}{r}\text { Needs } \\
\text { Attention }\end{array}$ \\
\hline $\mathrm{KQ}$ & $9 \%$ & $61 \%$ & $18 \%$ & $12 \%$ \\
\hline $\begin{array}{l}\mathrm{KQ} \\
2\end{array}$ & 0 & $29 \%$ & $53 \%$ & $18 \%$ \\
\hline $\mathrm{KQ}$ & 0 & $26 \%$ & $47 \%$ & $27 \%$ \\
3 & & & & \\
\hline
\end{tabular}

Areas of strength at the SQ level in KPA 6 show that the grounds are well maintained with $35 \%$ of schools rated as "Outstanding" and $44 \%$ of schools rated as "Good," and there is evidence of a regular cleaning schedule for classrooms, corridors, and toilets with $15 \%$ of schools rated "Outstanding" and $47 \%$ of schools rated "Good." Areas that are challenging for schools include SQ 3 regarding notices and displays that make students, teachers, and parents feel welcome $(77 \%$ of schools rated as "Variable" or "Needs Attention"), SQ5 regarding children's learning enhanced by teachers' use of instructional technologies (79\% of schools rated as "Variable" or "Needs Attention"), SQ 7 regarding well-documented systems for all health and safety work $(79 \%$ of schools rated as "Variable" or "Needs Attention"), and SQ 9 regarding appropriate checks on transport of students between home and school (73\% of schools rated as "Variable" or "Needs Attention"). SQ 7 was the most challenging with $50 \%$ of schools rated as "Needs Attention" for a system of documenting health and safety work.

\section{Discussion}

Assessing the quality of education in Indian schools based analysis of ratings from the AQS diagnostic tool provides detailed information about strengths and challenges for schools. Overall, performance was stronger on KPA 1 Leadership and Management than the other five KPAs. Analyses at the KQ level and SQ level provided specific information regarding strengths and areas that prove challenging. Every KPA, at the level of SQs had strengths as well as areas identified as "Variable" in performance or "Needs Attention." KPA 2 Teaching and Learning and KPA 4 The Curriculum had overall weaker performance and were the focus of more detailed analysis.

Across KPAs there appear to be related strengths and challenges. For example KPA 1 shows strength in providing information to parents about students' progress and KPA 5 shows a strength in involvement of families in the learning of students. It is also not surprising to find that challenging areas across KPAs include KPA 4 regarding the quality of learning beyond the classroom and KPA 5 regarding promoting an understanding and being involved in the local community. These areas may also be related to KPA 2 that showed an area of challenge in the quality of children's learning. While these areas are not equivalent, it seems likely that there would be connections among them. Similarly, KPA 3 shows a challenging area for schools involved the voice of the child in school, which may be related to the area of staff and students having a voice in how the school is run that was identified as a challenging area in KPA 1.

Specific analysis of KPA 2 and KPA 4 revealed additional insight into strengths and challenges in these two broad areas that had lower overall performance than the other KPAs. Areas of strength in KPA 2 Teaching and Learning included the classroom environment, while areas needing improvement included relationships in the classroom and school, and the quality of children's learning. 
Relationships in the classroom were identified as particularly in need of better classroom management and adult support of children's learning and social needs. Classroom management and differentiating instruction to support children's diverse learning needs are challenging areas for many teachers. The quality of children's learning could be improved by providing more opportunities for appropriately challenging work. This finding relates to what the Australian Council for Educational Research [9] and Shobha [10] reported regarding the disappointing results of India's limited participation in the Programme of International Student Assessment (PISA). Areas of strength in KPA 4 The Curriculum included the range of subjects taught, especially for private schools and schools with mixed management. Areas needing improvement in the curriculum included ways of extending and supporting learning beyond the classroom such as including visitors to the school and field trips for students to places outside of the school, and considering ways that would increase the enjoyment of learning for children.

The analysis completed on the first round of school reviews for the six KPAs in this study provides a baseline for the quality of education within this collection of schools.

\section{Strengths and limitations}

This research study includes a relatively small number of schools that willingly undertook the AQS process. This research begins to provide a more complete picture of the quality of education available to children in India by providing results across specific indicators in key areas of performance. This paper addressed six KPAs, with detailed analysis on two of those KPAs (Teaching and Learning, and The Curriculum) across two school variables (school management type, and geographic location). Analysis of other school variables may shed further insight on the quality of education provided to children. A limitation is that the number of schools participating in this study is a very small sample of schools, with the majority of schools in this study representing schools that are in urban locations and privately managed. Additional research that examines a larger collection of schools with broader representation of government schools and schools in rural locations is recommended.

\section{Conclusions}

The AQS process identified granular aspects of school performance that are related to quality. Initial findings from this study indicated the quality of education as defined by the AQS includes specific strengths in each of the six KPAs. While the overall ratings give a broad view of overall quality in an area, it is not enough to consider the general performance across the six KPAs. The detailed analysis from the AQS diagnostic tool around the SQs can provide specific guidance for schools to not only celebrate strengths, but also guidance for areas in which action could be taken to address areas that pose challenges to the quality of education.

Overall, the strongest performance was in the KPA 1 Leadership and Management, and specifically the KQ2 area of managing schools efficiently and effectively. The most challenging areas with the weakest performances All KPAs had some areas that were challenging. Detailed analysis of KPA 2 Teaching and Learning and KPA 4 The Curriculum show strength in the classroom environment and the range of subjects taught, while challenging areas included developing relationships among students and teachers, providing appropriate literacy and numeracy programs with challenging work for students, and extending learning for students beyond the classroom.

\section{Future directions}

Training school stakeholder teams to conduct self-reviews and encouraging schools to engage in continuous improvement is one step on the journey to improve the quality of education for all children. Increasing the understanding of what "good" looks like in education at an international level, with consideration for particular educational contexts, is also important. There is a need for examining the degree of understanding by school stakeholder teams of the AQS internationally benchmarked standards in relation to evidence they gather from their school. At the end of this 5-year study, differences in judgments from the school and external teams can be compared and analyzed to see whether, over time, these differences are minimized and/or disappear (e.g., after a second and third round of review). Analysis from subsequent rounds of review will provide insight and support for the extent to which schools take ownership in identifying areas for improvement, and then take action to improve the quality of education for their students.

\section{References}

[1] K. Kumar, and P.M. Sarangapani, "History of the Quality Debate", Contemporary Education Dialogue", vol. 2, no. 1, SAGE Journals, doi: 10.1177/097318490400200 103, July 2004, pp. 30-52.

[2] P. Velaskar, "Quality and Inequality in Indian Education: Some Critical Policy Concerns", Contemporary Education Dialogue, vol.7, no. 1, January 2010, pp. 58-93.

[3] Ministry of Human Resource Development, India, "Right to Education", 2009, http://mhrd.gov.in/rte (Access date: 30 December 2014). 
[4] M. D. M. Ehren, H. Altrichter, G. McNamara, and J. O'Hara, "Impact of School Inspections on Improvement of Schools-Describing Assumptions on Causal Mechanisms", Educational Assessment, Evaluation and Accountability, 25, 2013, pp. 3-43. doi:10.1007/s11092012 -9156-4

[5] V. Faubert, "School Evaluation: Current Practices in OECD Countries and a Literature Review", OECD Education Working Papers. doi:10.1787/218816 547156

[6] C. Gilbert, "The Annual Report of Her Majesty's Chief Inspector of Education, Children's Services and Skills 2007/08", Crown, 2008, https://www.gov.uk/government/ uploads/system/uploads/attachment_data/file/248394/1114 .pdf (Access date: 30 December 2014).

[7] M. Barber, and M. Mourshed, "How the world's bestperforming school systems come out on top", retrieved from http://mckinseyonsociety.com/how-the-worlds-bestperforming-schools-come-out-on-top/ (Access date: 15 December 2013).

[8] M. Mourshed, C. Chijioke, and M. Barber, "How the world's most improved school systems keep getting better", retrieved from http://mckinseyonsociety.com/ how-the-worlds-most-improved-school-systems-keepgetting-better/ (Access date: 15 December 2013).

[9] Australian Council for Educational Research (ACER), "ACER Releases Results of PISA 2009+ Participant Economies", retrieved from http://www.acer.edu.au/media/ article/acer-releases-results-of-pisa-2009-participanteconomies (Access date: 30 December 2014).

[10] J. Shobha, "PISA vasool this year?", The Times of India, retrieved from http://timesofindia.indiatimes.com/ home/stoi/special-report/PISA-vasool-thisyear/articleshow/ 16318939.cms? (Access date: 20 September 2012). 